\title{
Self-centeredness or patient-centeredness- final year nursing students' experiences of learning at a clinical education ward
}

\author{
Katri Manninen ${ }^{1}$, Max Scheja $^{2}$, Elisabet Welin Henriksson ${ }^{3}$, Charlotte Silén ${ }^{1}$ \\ 1. Department of Learning, Informatics, Management and Ethics, Karolinska Institutet, Stockholm, Sweden. \\ 2. Department of Education, Faculty of Social Science, Stockholm University, Stockholm, Sweden. \\ 3. Department of Neurobiology, Care Sciences and Society, Karolinska Institutet, Stockholm, Sweden.
}

Correspondence: Katri Manninen. Address: Department of Learning, Informatics, Management and Ethics, Karolinska Institutet, SE- 171 77, Stockholm, Sweden. Email: katri.manninen@ki.se

Received: April 30, 2013 Accepted: May 27, $2013 \quad$ Online Published: August 19, 2013

DOI : 10.5430/jnep.v3n12p187 URL: http://dx.doi.org/10.5430/jnep.v3n12p187

\section{Abstract}

Background: Different types of clinical education wards with the aim of facilitating transition from student to professional have been established giving students more autonomy and responsibility. Studies report positive effects but deeper understanding concerning how clinical education wards can contribute to learning for students nearing graduation is needed.

Aim: To explore final year nursing students' experiences of learning when they are supported to take care of patients independently.

Methods: The context for this study was a clinical education ward for nursing students at a university hospital in Sweden. Individual and group interviews with 18 students of 29 eligible students were conducted after their clinical practice. The data was analyzed using qualitative content analysis with a focus on students' experiences of their encounters with patients, supervisors, students and other professionals.

Results: The two main themes appeared as important aspects influencing final year students' learning, uncertainty as a threshold and experiencing engagement. Sub-themes characterizing uncertainty as a threshold were self-centeredness and ambivalence describing the patient from the perspective of performing nursing tasks. Sub-themes characterizing experiencing engagement were creating mutual relationship and professional development. Caring for patients with extensive need for nursing care helped the students to become patient-centered and overcome the threshold, experience engagement and authenticity in learning the profession.

Conclusions: A clinical education ward may enhance the students' experience of both external and internal authenticity enabling meaningful learning and professional development. It is important to acknowledge final year nursing students' need for both challenges and support in the stressful transition from student to professional. Therefore, an explicit pedagogical framework based on patient-centered care and encouraging students to take responsibility should be used to help the students to overcome self-centeredness and to focus on the patients' needs and nursing care.

\section{Key words}

Clinical education ward, Self-centeredness, Patient-centeredness, Nursing students, Authenticity, Threshold, Engagement 


\section{Introduction}

The clinical learning environment has a great impact on students' learning and professional development. Studies have shown that attitudes, communication, supervision and support are important aspects for students' experiences of learning in clinical environments ${ }^{[1,2]}$. One way to support students' learning is a clinical education ward which is a learning environment that focuses both on students' learning and taking care of patients ${ }^{[3,4]}$.

This study forms part of a larger project exploring learning at a clinical education ward where nursing students on different levels have a clinical placement. This education ward has a pedagogical framework aiming at activating and supporting students' learning and development. A previous study on nursing students' learning early in their education, suggests that students create their own relationships with patients ${ }^{[5]}$ - relationships that constitute the basis for their learning and are fundamental to the students' sense of belonging in the professional caring team. The present study focuses on final year students' learning in the context of a clinical education ward.

Studies show that the transition from student to graduate health care professional is stressful and that students feel unprepared for their professional role. This transition process is difficult for students to cope with; it can be perceived as overwhelming and can in some cases cause fear in students. So students need clinical environments where this transition can be facilitated by letting them meet challenges and responsibilities with support from clinical supervisors ${ }^{[6-10]}$. Bradbury-Jones and colleagues ${ }^{[11]}$ found that first year nursing students feel empowered when they are valued as learners and as individuals. Effective supervision and a supportive atmosphere increase their empowerment. Lilja Andersson and Edberg ${ }^{[12]}$ also stress the importance of acknowledgement especially towards the end of an educational program. To be acknowledged means that students are confirmed in their professional role as future nurses and thus trusted to act more independently. Furthermore, experiential learning and reflection support students' learning process. An active participant in a community of practice, for instance a clinical learning environment, learns by belonging, doing, becoming and experiencing complex issues by moving from legitimate peripheral participants to full participation through application and support ${ }^{[13-15]}$.

Studies of clinical education environments, such as interprofessional training wards, student wards and peer-learning, show that they have an impact on students' learning about collaboration and their professional role. Allowing students more autonomy and responsibility tends to increase their self-confidence, and develop the ability to think critically and solve problems. In sum these forms of supportive clinical environments tend to promote students' transition from student to registered nurse ${ }^{[16-20]}$. Length of the clinical placement has been found to be of importance to gain a holistic experience of nursing care, including relationship to the patient, as well as understanding the professional role ${ }^{[1]}$.

While research has described aspects that are important to the students' learning in clinical environments there is a lack of deeper knowledge of students' learning processes from the students' perspective. Learning is a complex phenomenon and can be described from different perspectives. No single learning theory grasps all the dimensions of learning and in recent years a multifaceted understanding of learning, including cognitive, emotional and socio-cultural perspectives, has taken place ${ }^{[21-23]}$. According to contemporary learning theories, learning is an active construction process and the individual's life world is the basis for the individual's understanding, thinking and action ${ }^{[21]}$. Learning, in this study, is understood as a transformative and meaning making construction process about new or modified interpretations of perceptions and experiences ${ }^{[24]}$. Meaningful learning involves a process of knowledge construction where students try to make sense of their experiences interacting with other people and the environment ${ }^{[21,23,25]}$. Assessment and reformulation of "meaning perspectives" is a core activity in learning and constitutes the individual practice ${ }^{[24]}$. Learning is about understanding, seeing something in a different way and changing as a person ${ }^{[26]}$. To stimulate learning attention has to be paid to the individuals' driving forces for learning, which means to understand the students' motivation and experiences as a resource for the learning process ${ }^{[22,23]}$. This implies what Marton and Booth ${ }^{[26]}$ describe as a deep approach to learning, characterized by active engagement and meaning-making. Previous research ${ }^{[5]}$ focusing on students' experience of learning early on in their nursing education underscored students' mutual relationships with the patients and experiences 
of belongingness as crucial for meaningful learning. However, to broaden our understanding and extend the transferability of these results it is necessary to understand how clinical education wards can contribute to learning for students at later stages in their education. As the literature show ${ }^{[1,6-8,10]}$ the latter part of the nursing education, on the edge of becoming a professional nurse, is stressful with demands on students to grasp the wholeness of nursing care.

\section{Aim}

The purpose of this study was to explore final year nursing students' experiences of learning at a clinical education ward where students are supported to independently take care of patients.

\section{Methods}

\subsection{Study design}

This study forms part of a larger project exploring learning at a clinical education ward from the perspective of students, patients and supervisors using a qualitative and interpretative research approach. This approach makes it possible to explore experiences and to deepen the understanding of student's learning in clinical settings ${ }^{[27-29]}$.

\subsection{Context}

In Sweden, the nursing degree program is three years and leads up to a Bachelor's degree. The program includes both theoretical classes and clinical practice. Nursing students have various clinical placements at hospitals and in primary care throughout the program. The clinical practice can be organized in different ways at universities and in clinical settings but the intentions are to promote consolidation of theoretical and practical knowledge and skills into a new entity. The setting for this study was a clinical education ward for nursing students at a department of infectious diseases at a university hospital. There are eight beds at the ward and the students take care of the patients by working both independently and together with other students with support from supervisors. Patient safety is guaranteed by the supervisors. Supervision of students is based on making students part of the caring team, focusing on meaning making learning processes and students' own responsibility in learning ${ }^{[24,25]}$. Students are allowed to act independently as professional nurses, but the supervisors are present and support the students when needed. The overall aim is to train students for their profession, to practise teamwork and to practise interprofessional collaboration. Prior to the clinical practice at the ward the students participate in an introductory session, and throughout their clinical practice there is a reflection session at the end of every shift. Four nurses, a nursing assistant, a clinical lecturer and a physician serve as supervisors. In addition, a physiotherapist, an occupational therapist, a counselor and a dietician are associated with the ward. Fifteen students are simultaneously doing their clinical practice at the ward for six weeks. Students can be placed at the clinical education ward either at the beginning or at the end of their education.

\subsection{Participants}

Twenty-nine nursing students in their fifth term completed clinical practice at the ward during two semesters and were invited to participate in the study. Both oral and written information were given to all eligible students at the introductory session to the clinical placement. Eighteen students agreed to participate: 17 female and one male with an age ranging from 21-39 years, median age 27. Two group interviews with five participants in each and eight individual interviews were conducted between five days and four weeks after the clinical practice.

\subsection{Data collection}

Semi-structured interviews were conducted by the first author after the students had completed their clinical practice. To get rich data and ensure trustworthiness, the students' experiences were probed in depth and both individual and group interviews were conducted in order to collect data of various kinds to illuminate the students' experiences of learning at the ward ${ }^{[30]}$. Individual interviews may have facilitated the participants to express their feelings and thoughts, whereas the 
interaction between participants in the group interviews may have promoted their recall and brought forth diverse viewpoints ${ }^{[30,31]}$. The interview guide included four questions on how students experienced their encounters with 1) patients, 2) staff members, 3) other students and 4) other professionals at the ward. The interviewer introduced these questions in both the individual and the group interviews and asked the students to discuss and reflect on how they perceived these encounters. The interviews were audio-taped, lasted 45-90 minutes and were transcribed verbatim.

\subsection{Data analysis}

Qualitative content analysis is a method for interpretation of the content of text data using a systematic coding process and identifying themes focusing on the manifest content or the latent content of the data ${ }^{[28,29,32]}$. Interviews were regarded as communicative acts between the interviewer and the participants ${ }^{[31]}$. In this study, the qualitative content analysis with emphasis on the latent content was used. The interpretation of data involved moving from the manifest to the latent by ascribing meaning to the manifest content.

Data analysis was conducted in several steps beginning with the first author reading through transcripts several times to identify meaning units, sorting them into the four domains from the interview guide and condensing the text. The condensed text was read by all authors and coded and analyzed further by two authors (KM, CS). This analysis resulted in 11 sub-categories and four categories. These categories describe the manifest content, that is, what was said in the interviews. The analysis proceeded with interpretation of the categories conducted by two authors (KM, CS) and resulted in main themes and sub-themes. The themes and sub-themes were discussed by all authors until consensus was reached resulting in two main themes and four sub-themes which express the interpreted meaning of what was said. An overview of categories and themes is presented in Table 1 . The data analysis has been a movement back and forth throughout the analysis.

Table 1. Overview of Categories and Themes

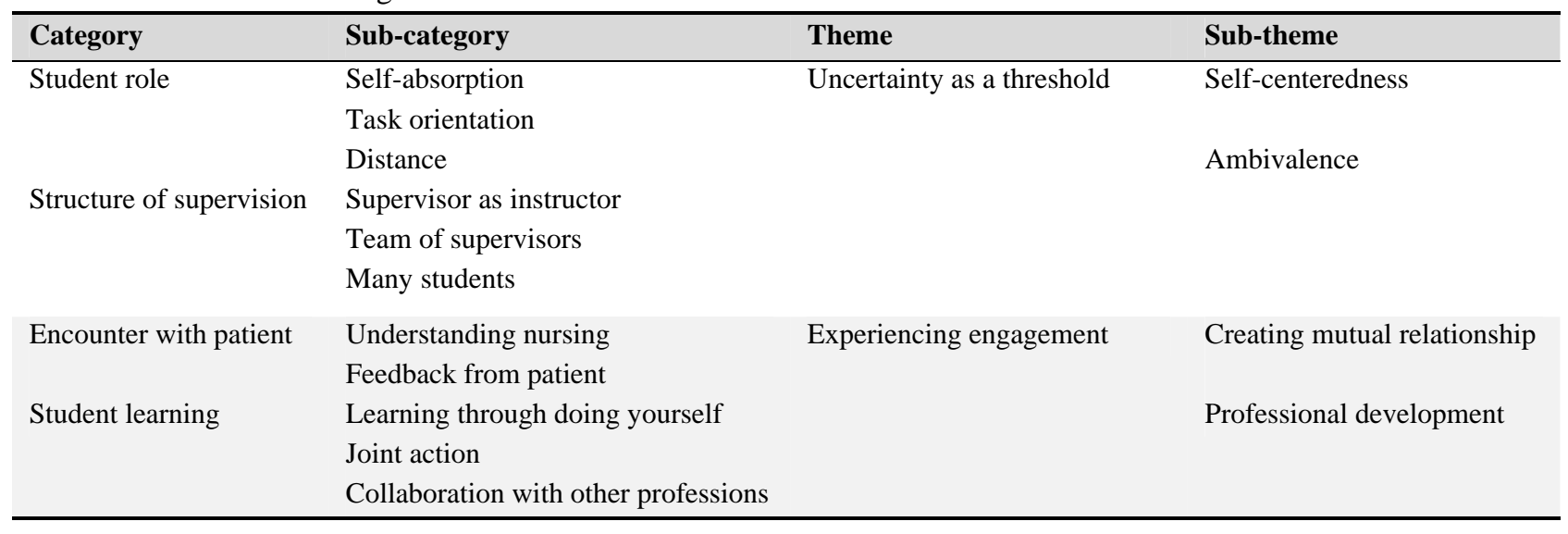

Note. Categories and sub-categories describe what was said in the interviews, i.e. the manifest content of the data. Themes and sub-themes are an interpretation of categories and an expression for the latent content of the interviews.

\subsection{Ethical considerations}

This study was carried out in accordance with the declaration of Helsinki ${ }^{[33]}$ and approved by The Regional Ethical Review Board. Participation was voluntary and participants were informed about the study both orally and in writing. The information concluded that the study would not affect their studies during the clinical practice and they were able to decline to participate at any time without any questions asked. They were also informed about the confidentiality regarding the gathered data and that they would not be identified. Informed written consent was obtained from the participants prior to the interviews. 


\section{Results}

The analysis resulted in two main themes: uncertainty as a threshold and experiencing engagement, influencing final year students' learning. The feeling of uncertainty was characterized by the sub-themes self-centeredness and ambivalence. Uncertainty constituted a threshold for engagement, which means that the students showed little interest in patients. Experiencing engagement included the sub-themes creating a mutual relationship with the patient and professional development. This engagement helped students to overcome the threshold, resulting in professional development on the way to becoming a nurse. An overview of the main themes and sub-themes is presented in Table 1.

\subsection{Uncertainty as a threshold}

Uncertainty was expressed in different ways related to the student role and how the supervision was organized. The sub-themes self-centeredness and ambivalence are the salient expressions for the feeling of uncertainty in students' relationships. In their relationships with patients and other students they showed self-absorption and distance. Students focused on carrying out different tasks and handling the fact that there was a group of students at the ward. Relationships with supervisors were marked by dependency and ambivalence.

\section{Self-centeredness}

The most significant features of the students' self-centeredness were that students saw the patient as an object and their learning was directed towards what they needed to do as nurses. The self-centeredness seemed to emanate from a wish and intention to learn everything a nurse might be expected to master. Students emphasized that being responsible for just a few patients could jeopardize their own development and when encountering patients they had a role focusing on carrying out the tasks. Patients were described from the perspective of different tasks.

My encounters with patients were quite simple, uncomplicated...They were aware of the disease they had, they knew what was about to happen...If I told them that they needed something... so they agreed and I did it. (Student 6)

Uncertainty and self-centeredness were also shown in discussions about severely ill patients. Students' interest in patients depended on severity of diseases and whether there were medical-technical tasks to carry out. The students expressed that being professional was to focus on what can be done at the ward for the patient and also to make demands on the patient. They meant that it is unprofessional to be too kind and soft. Students also described difficulties feeling empathy for patients that showed poor compliance to the treatment. If the patient had a complex medical condition or the students felt that they became too close to the patient, they might have chosen not to take care of the patient.

I didn't want to take care of her, students who felt that they want to do it could take care of her... If she is feeling bad it is incredibly important that the person who takes care of her can handle the situation. (Student 15)

Students also meant that the supervisors were responsible for providing sufficient learning opportunities and for guiding students through the work that had to be done. Yet they did not communicate this feeling of uncertainty to supervisors. On the one hand, the students expected the supervisors to understand their feelings, but on the other hand, they did not want to reveal their feelings of helplessness to the supervisors.

Especially in the morning, it would have been nice to sit down with someone and get some structure, little help for today, because this was something I felt that I failed at all the time. Things happened all the time and I never managed to put everything together. (Student 10)

\section{Ambivalence}

In their relationships with the supervisors, the students wanted to be independent, while at the same time they wanted to be given instructions. Students perceived the supervisors as an instructor and a model to follow. They were supposed to give 
the students a structure for the shift, to teach and instruct. Students felt that the supervisors were supposed to be a resource to them, but they were not available when needed.

I'm here to learn, and if you have noticed that I can't manage this, why don't you teach me without me having to ask for it... I'm not worried about this; I know I'll manage after practicing. But if you think that this is not good enough I would like you to tell me: this is what you should practice; this is how it should be done. (Student 8)

Students were willing to show their competence and ability to manage by themselves. At the same time, the students felt that they needed help and support. Students were afraid of hurting patients and failing. They did not dare to take risks although they felt that they had the ability to do what was needed. Students were longing for feedback from supervisors but they expressed that either they did not get it or they did not bother to ask for it. Both ways resulted in the students not knowing whether they had performed correctly.

I hated this feeling when I went in to a patient to carry out something that I didn't feel comfortable doing...I didn't feel comfortable asking for help either. Because I had this feeling that I should find it out for myself or this is something I was supposed to know. (Student 12)

At the same time the students described having a team of competent and interested supervisors knowing the students' needs. The team of supervisors allowed the students to be independent, encouraged them to take responsibility and reflect on what they were doing. They helped the students manage situations rather than taking over and doing everything themselves. The students perceived that the supervisors saw the whole rather than details and they felt safe having several supervisors.

I think that these goals were great... because I had to think about what I need to practice more and also they know my weaknesses ...I felt that they paid attention to my goals... they tried to push me and they used them to make me to develop and improve. (Student 1 )

Ambivalence also described students' relationships with their peers. Students expressed that it was positive to work together with other students, but there were too many at the ward creating confusion and obstacles for their learning. Relationships with other students were described as beneficial but also competitive. On the one hand, there were many students at the ward, creating more time for the patients and possibility for collaboration.

This man with a depression... started to feel better, not only because I told him to call his brother but because we all worked together for him; we drew up the curtains, we told him to get up and watch TV outside the patient room...even things like first signs of a pressure wound...that we assisted to mobilize and rub the ointment and things. (Student 18)

On the other hand, students experienced competition in medical-technical tasks and the attention of the supervisors resulted in feelings of not getting enough supervision. Different levels of students simultaneously at the ward were experienced as a hindrance. Students described that they were repeating tasks they already could do and the focus was on the basics of nursing and caring, adapted to the needs of the lower level students. The final year students perceived that they had other needs and wanted advanced learning, not the basics.

There was this patient with central vein access, but a second year student took the patient and this particular task is in our syllabus... and also this other central access... I never had the opportunity to handle them. I feel that supervisors should have controlled these things more. (Student 13) 


\subsection{Experiencing engagement}

Uncertainty appeared to constitute a threshold for engagement concerning patients as subjects. The students who managed to overcome this threshold focused on patients and learned how nursing can affect the patients' condition and well-being. They experienced engagement when taking care of a patient with extensive need for nursing interventions. In these situations they created mutual relationships with the patients and experienced professional development and learning through patients, by doing things on their own and through collaboration with other professions.

\section{Creating mutual relationship}

The students created a relationship with the patient when they experienced the patient as a subject. Students described how patients with need for extensive nursing interventions helped them to create a mutual relationship with the patient. They stayed and communicated with the patients, observed changes and followed the patients throughout their stay at the ward. They felt that they had to make the patients feel safe. The students expressed that through these relationships they learned nursing and they understood that nursing makes a difference for patients. Students were acknowledged when they saw changes and improvements in patients' well-being.

We held her hand and practically waited for her to die. Then we noticed that she became a little bit angry and started to show rage, which was good... if you can show anger you can also start to recover...that's how it all started... She tried to hit us and scratch and pinch us... and we thought... damn it! Now we'll get rid of all wounds and everything. She had a lot of... terrible wounds in her genitals... bloody hemorrhoids. All that was gone... you couldn't see any trace of them... after two weeks....Now I know that nursing matters a lot. I didn’t know. I thought that only ointments and injections would make a difference. (Student 9)

Students described that patients had different needs. Some patients needed distinct information and they wanted everything to be handled quickly and effectively, whereas others expressed a need for students' presence, not just carrying out the tasks. Students experienced understanding and supportive feedback directly from patients.

I took care of this patient who was isolated because of suspected tuberculosis... ... so you stayed there for a longer time but not as often as with another patient and then you noticed the difference when you sat down and just listened to the patient and you were there for him. The expression in his face became different, his breathing improved and everything... This opened my eyes, how much it matters. (Student 17)

\section{Professional development}

Professional development meant understanding the complex reality, approaching the wholeness of nursing care and to be able to collaborate with other professionals. Students meant that they learned by performing independently with support. They were allowed to train independently and found a pattern that worked for them. There was a plan for their development and they felt needed at the ward. Students expressed how they, towards the end of the placement, reached a level on which they could see what needed to be done and they felt confident enough to handle different situations. Gaining more independence and recognizing situations, they learned how to link together their previous experiences and knowledge to a new whole.

I pulled myself together... more than I have done before. Now I'll manage... and the supervisor told me at the final assessment that I didn't show the patients my insecurity... well, I have managed to be professional. Outside the patient's room I was so insecure... they [supervisors] saw the difference. So it was a transformation, obviously. (Student 11)

Collaboration with other professions meant mainly collaboration with the physicians at the ward. Students learned how they could work together for the patients. At the rounds, students learned how nursing and medicine make a whole. This collaboration was about learning each others' tasks and collaboration was needed for planning and follow-up for the 
patients. In this collaboration, students felt that their tasks were to prepare the patient, to listen, to remember and to carry out the decided interventions. The students expressed that other professionals came from outside and they saw other needs.

You make it an occasion for the patient, what should we do now and how do we go ahead so you really raise everything... for the doctors' sake, so they also see this perspective and you can get answers, does this patient really need this medicine or not? (Student 15)

When final year nursing students, practicing at a clinical education ward, focused on patients, they overcame feeling of uncertainty and the threshold for engagement in patient care, resulting in understanding the complexity of nursing and starting to become a professional nurse.

\section{Discussion}

This study shows that final year nursing students engage in patient care and experience learning if they are able to overcome the threshold of uncertainty. The feeling of uncertainty is characterized by self-centeredness, objectifying the patients and ambivalence towards patient care, supervisors and peers. The students want to be independent, but they do not dare to act without instructions from supervisors and peer students are seen as competitors. Taking care of patients in need of extensive nursing interventions leads to engagement and a mutual relationship is created with the patient. This relationship helps the students to overcome their uncertainty and becomes a basis for their development as nurses.

These findings are in contrast to previous research on first-year students' experiences of learning in the same setting ${ }^{[5]}$. First year students' learning was based on mutual relationships with the patients and the feeling of belonging in caring for the patients together with supervisors, peers and other professions at the ward. The striking differences are that the final year students are self-centered instead of patient-centered and they have difficulties finding their role and place at the ward. Self-centeredness and feelings of not belonging tend to obstruct students' learning processes and they become uncertain and ambivalent about what and how to learn. Their ambition of being independent turns into dependence on supervisors' guidance.

How can these differences between first and final year students be understood? We suggest that the feeling of uncertainty can be explained by the fact that the students are nearing their graduation and have started the transition from student to professional nurse. At the clinical education ward, they become aware of the complex reality, which they will soon enter as active participants without having someone to rely on for advice on how to tackle challenges. This is a stressful process and students are feeling vulnerable, which is also described in two Australian studies from 2004 and $2007^{[6,7]}$. The clinical education ward aims to facilitate students' transition from student to professional in a real but safe setting. Faced with the responsibility of taking care of patients as a nurse the students seem to experience a threat but not the safety. The reaction is to distance themselves from the patients, the supervisors and peers and put nursing tasks up front looking for guidance and support.

Interestingly, when students take care of patients that need extensive nursing interventions, they experience engagement in learning through nursing care. This is similar to what we found in the study of first-year students' experiences ${ }^{[5]}$. First year students experienced both external and internal authenticity. External authenticity is about working at a real ward with real patients. The internal authenticity is characterized by a perceived real and genuine relationship between the student and the patient. Students feel they make a difference in caring for the patient. McCune ${ }^{[34]}$ who explicitly studied students' experiences of authenticity in a learning environment in UK 2009 underscores that authentic learning experiences influence students' identity and willingness to engage in their studies. Based on the present study, final year students experience only external authenticity until they care for patients with the need for extensive nursing interventions. In these situations, the students become involved and the patient becomes the centre instead of themselves. When they overcome the threshold of uncertainty, they approach the complexity of nursing and begin to feel that they manage to handle 
situations related to their future profession as nurses. When this happens, they also find the collaboration with the supervisors, the peers and other professionals as contributing to their learning.

The feeling of uncertainty stands out as an obstacle for learning but it is possible for students to overcome it. This phenomenon has similarities with threshold concepts described in two studies from UK 2005 by Meyer and Land ${ }^{\text {[35] }}$ and Clouder ${ }^{[36]}$. Threshold concepts are specific concepts which are identified as essential in the acquisition of thinking and learning and without crossing the threshold learning cannot progress. Crossing such a threshold involves students changing their outlook on what it means to learn in a particular learning environment and also reaching a more complex level of understanding. In this study emotional aspects of learning seem to be important, while previous discussions related to threshold concepts stress cognitive understanding. One assumption is that transformative learning and meaning making construction processis ${ }^{[24,25]}$ are the result of challenges, support and feedback provided in safe and authentic settings which is also discussed by Kaufman and Mann ${ }^{[37]}$. When students are challenged by a patient with complex needs, they start to collaborate and they acknowledge the importance and meaning of nursing as well as their own role as future nurses. In these situations, students also experience development; they are supported in acting independently, resulting in the feeling that they are confident enough to handle different situations and find solutions.

One reason for final year students not being patient-centered could be previous experiences of poor role models and task-oriented supervisors. This is an issue worth looking into more deeply. Losing the patient-centeredness during the education has also been found among medical students in Greece 2007 and in Netherlands $2010{ }^{\text {[38, 39] }}$. A supportive environment focusing on students' learning and patient-centered role models can enhance students' patient-centeredness throughout the education ${ }^{[40]}$.

Supervision based on patient-centeredness and allowing students to gain independence by providing both challenges and support stand out as crucial for the students to manage.

The complex learning processes of final year nursing students needs to be taken into account by supervisors at a clinical education ward. The supervisors should be aware that the students' learning process is influenced by the need for both challenges and support. Hodges study from USA $2011^{[41]}$ stresses the importance of pushing students out of their comfort zone, resulting in achievements in teamwork and professionalism, which is in line with findings in this study. Silén ${ }^{[42]}$ also points out that a pedagogical framework where supervisors support and challenge the students both individually and as a group can enhance their ability to be responsible and independent in their learning process.

\section{Methodological considerations}

To enhance trustworthiness including dependability and credibility different actions were taken. The participants with different experiences, that is, students who had completed clinical practice at the ward, were invited to participate. Although both individual and group interviews were conducted the same interview guide was used in all interviews ${ }^{\text {[28] }}$. One of the authors (KM) had a specific pre-understanding of the setting which could have influenced the interpretation of data. To increase trustworthiness investigator triangulation ${ }^{[27]}$ was used engaging all authors in the analysis. The data has been read, re-read and discussed by all authors until consensus was reached. The different experiences of the authors made it possible to challenge each other's assumptions and constantly return to data for confirmation of interpretations. This study has been conducted at one hospital which has to be considered when judging the transferability of the results and accordingly the context has been described at some length ${ }^{[28]}$. However, relating the results to the concepts of authenticity and threshold as well as learning theories emphasizing transformative learning and meaning making construction learning process ${ }^{[21,24,25]}$ seeks to enhance the applicability of the results in different contexts.

\section{Conclusions}

A key to student learning in clinical practice seems to be the experience of both external and internal authenticity. Final year students experience feeling of uncertainty involving self-centeredness and ambivalence and this constitutes a 
threshold for engagement in patient care and an experience of only external authenticity. A clinical education ward with a pedagogical framework which allows students to be part of the caring team and to take responsibility for their own learning enhances meaning making learning processes and transformative learning. Students are stimulated to create mutual relationships with patients and to collaborate with other students and other professionals resulting in an experience of also internal authenticity. Students overcome the threshold for engagement and start to become nurses. A clinical implication of this study is that the pedagogical framework at a clinical education ward should be explicit, patient-centered and adapted to students on different levels, taking into account the final year nursing students' need for both challenges and support in a stressful transition from student to professional.

Studies from the perspectives of patients and supervisors are needed in order to gain deeper and more holistic understanding of the students' learning process at a clinical education ward.

\section{Acknowledgements and funding}

Financial support was provided through grants from the regional agreement on medical training and clinical research (ALF) between Stockholm County Council and Karolinska Institutet.

\section{Competing interests}

The authors declare that they have no competing interests.

\section{References}

[1] Warne T, Johansson UB, Papastavrou E, Tichelaar E, Tomietto M, van den Bossche K, et al. An exploration of the clinical learning experience of nursing students in nine European countries. Nurse Education Today. 2010; 30(8): 809-815. http://dx.doi.org/10.1016/j.nedt.2010.03.003.

[2] Johansson UB, Kaila P, Ahlner-Elmqvist M, Leksell J, Isoaho H, Saarikoski M. Clinical learning environment, supervision and nurse teacher evaluation scale: psychometric evaluation of the Swedish version. Journal of Advanced Nursing. 2010; 66(9): 2085-2093. http://dx.doi.org/10.1111/j.1365-2648.2010.05370.x

[3] Ponzer S, Hylin U, Kusoffsky A, Lauffs M, Lonka K, Mattiasson AC, et al. Interprofessional training in the context of clinical practice: goals and students’ perceptions on clinical education wards. Medical Education. 2004; 38(7): 727-736. http://dx.doi.org/10.1111/j.1365-2929.2004.01848.x

[4] Mulready-Shick J, Kafel KW, Banister G, Mylott L. Enhancing quality and safety competency development at the unit level: an initial evaluation of student learning and clinical teaching on dedicated education units. Journal of Nursing Education. 2009; 48(12): 716-719. http://dx.doi.org/10.3928/01484834-20091113-11

[5] Manninen K, Welin Henriksson E, Scheja M, Silén C. Authenticity in learning nursing students' experiences at a clinical education ward. Health Education. 2013; 113(2): 132-143. http://dx.doi.org/10.1108/09654281311298812

[6] McKenna LG, Green C. Experiences and learning during a graduate nurse program: an examination using a focus group approach. Nurse Education in Practice. 2004; 4(4): 258-263. http://dx.doi.org/10.1016/j.nepr.2004.01.004

[7] Newton JM, McKenna L. The transitional journey through the graduate year: a focus group study. International Journal of Nursing Studies. 2007; 44(7): 1231-1237. http://dx.doi.org/10.1016/j.ijnurstu.2006.05.017

[8] Ralph E, Walker K, Wimmer R. Practicum and clinical experiences: postpracticum students’ views. Journal of Nursing Education. 2009; 48(8): 434-440. http://dx.doi.org/10.3928/01484834-20090518-02

[9] Brennan N, Corrigan O, Allard J, Archer J, Barnes R, Bleakley A, et al. The transition from medical student to junior doctor: today's experiences of Tomorrow's Doctors. Medical Education. 2010; 44(5): 449-458. http://dx.doi.org/10.1111/j.1365-2923.2009.03604.x

[10] Higgins G, Spencer RL, Kane R. A systematic review of the experiences and perceptions of the newly qualified nurse in the United Kingdom. Nurse Education Today. 2010; 30(6): 499-508. http://dx.doi.org/10.1016/j.nedt.2009.10.017

[11] Bradbury-Jones C, Sambrook S, Irvine F. Empowerment and being valued: a phenomenological study of nursing students' experiences of clinical practice. Nurse Education Today. 2011; 31(4): 368-372. http://dx.doi.org/10.1016/j.nedt.2010.07.008 
[12] Lilja Andersson P, Edberg AK. Swedish nursing students experience of aspects important for their learning process and their ability to handle the complexity of the nursing degree program. Nurse Education Today. 2012; 32(4): 453-457. http://dx.doi.org/10.1016/j.nedt.2011.05.011

[13] Wenger E. A social theory of learning. In Contemporary theories of learning. K. Illeris, ed. London: Routledge; 2009; $209-218$.

[14] Smedley A, Morey P. Improving learning in the clinical nursing environment: perceptions of senior Australian bachelor of nursing students. Journal of Research in Nursing. 2010; 15(1): 75-88. http://dx.doi.org/10.1177/1744987108101756

[15] Mann KV. Theoretical perspectives in medical education: past experience and future possibilities. Medical Education. 2011; 45(1): 60-68. http://dx.doi.org/10.1111/j.1365-2923.2010.03757.x

[16] Nash R, Lemcke P, Sacre S. Enhancing transition: an enhanced model of clinical placement for final year nursing students. Nurse Education Today. 2009; 29(1): 48-56. http://dx.doi.org/10.1016/j.nedt.2008.06.004

[17] Bourgeios S, Drayton N, Brown AM. An innovative model of supportive clinical teaching and learning for undergraduate nursing students: the cluster model. Nurse Education in Practice. 2011; 11(2): 114-118. http://dx.doi.org/10.1016/j.nepr.2010.11.005

[18] Pelling S, Kalen A, Hammar M, Wahlström O. Preparation of becoming members of health care teams: findings from a 5-year evaluation of a student interprofessional training ward. Journal of Interprofessional Care. 2011; 25(5): 328-332. http://dx.doi.org/10.3109/13561820.2011.578222.

[19] Ruth-Sahd LA. Student nurse dyads create a community of learning: proposing a holistic clinical education theory. Journal of Advanced Nursing. 2011; 67(11): 2445-2454. http://dx.doi.org/10.1111/j.1365-2648.2011.05690.x

[20] Hellström-Hyson E, Mårtensson G, Kristofferzon ML. To take responsibility or to be an onlooker. Nursing students’ experiences of two models of supervision. Nurse Education Today. 2012; 32(1): 105-110. http://dx.doi.org/ 10.1016/j.nedt.2011.02.005

[21] Illeris K. A comprehensive understanding of human learning. In Contemporary theories of learning. K Illeris, ed. London: Routledge; 2009; 7-20.

[22] Knowles MS, Swanson RS, Holton EF. The adult learner. 7th ed. New York: Routledge, 2012.

[23] Mann K, Dornan T, Teunissen PW. Perspectives on learning. In Medical Education. T. Dornan ed. London: Churchill Livingstone; 2011; 18-35. PMid:21280987

[24] Mezirow J. An overview on transformative learning. In Contemporary theories of learning. K.Illeris, ed. London: Routledge; 2009; 90-105.

[25] Mayer RE. Rote versus meaningful learning. Theory into Practice 2002; 41 (4): 226-232.

http://dx.doi.org/10.1207/s15430421tip4104_4

[26] Marton F, Booth S. Learning and Awareness. London: Routledge; 1997.

[27] Denzin NK, Lincoln YS. Introduction: the discipline and practice of qualitative research. In Collecting and Interpreting Qualitative Materials. NK Denzin and YS Lincoln, eds. 3rd ed. Los Angeles: Sage, 2008; 1-43.

[28] Graneheim UH, Lundman B. Qualitative content analysis in nursing research: concepts, procedures and measures to achieve trustworthiness. Nurse Education Today. 2004; 24(2): 105-112. http://dx.doi.org/10.1016/j.nedt.2003.10.001

[29] Elo S, Kyngäs H. The qualitative content analysis process. Journal of Advanced Nursing. 2008; 62(1): 107-115. http://dx.doi.org/10.1111/j.1365-2648.2007.04569.x

[30] Fontana A, Frey JH. The Interview: from neutral stance to political Involvement. In Collecting and Interpreting Qualitative Materials. NK Denzin and YS Lincoln, eds. 3rd ed. Los Angeles: Sage, 2008; 115-159.

[31] Kvale S, Brinkmann S. Interviews. Learning the Craft of Qualitative Research Interviewing. 2nd ed. Los Angeles: Sage, 2009.

[32] Sandelowski M.Whatever happened to qualitative description? Research in Nursing \&Health. 2000; 23(4): 334-340. http://dx.doi.org/10.1002/1098-240X(200008).

[33] World Medical Association Declaration of Helsinki. "Ethical Principles for Medical Research Involving Human Subjects" http://www.wma.net/en/30publications/10policies/b3/

[34] McCune V. Final year biosciences students’ willingness to engage: teaching-learning environments, authentic learning experiences and identities. Studies in Higher Education. 2009; 34(3): 347-61. http://dx.doi.org/10.1080/03075070802597127

[35] Mayer JHF, Land R Threshold concepts and troublesome knowledge (2): Epistemiological considerations and a conceptual framework for teaching and learning. Higher Education. 2005; 49(3): 373-388. http://dx.doi.org/10.1007/s10734-004-6779-5

[36] Clouder L. Caring as a "threshold concept”: transforming students in higher education into (health) care professionals. Teaching in Higher Education. 2005; 10(4): 505-517. http://dx.doi.org/10.1080/13562510500239141

[37] Kaufman DM, Mann KV Teaching and learning in medical education: how theory can inform practice. In Understanding Medical Education. Evidence, Theory and Practice. T. Swanwick, ed. Oxford: Wiley-Blackwell, 2010, 16-36. http://dx.doi.org/10.1002/9781444320282 
[38] Tsimtsiou Z, Kerasidou O, Efstathiou N, Papaharitou S, Hatzimouratidis K, Hatzichristou D. Medical students' attitudes toward patient-centered care: a longitudinal survey. Medical Education. 2007; 41(2): 146-153. http://dx.doi.org/10.1111/j.1365-2929.2006.02668.x

[39] Bombeke K, Symons L, Debaene L, De Winter B, Schol S, Van Royen P. Help, I’m losing patient- centeredness! Experiences of medical students and their teachers. Medical Education. 2010; 44(7): 662-673. http://dx.doi.org/10.1111/j.1365-2923.2010.03627.x

[40] Suikkala A, Leino-Kilpi H, Katajisto J. Factors related to the nursing student-patient relationship: the students' perspective. Nurse Education Today. 2008; 28(5): 539-549. http://dx.doi.org/10.1016/j.nedt.2007.09.004

[41] Hodges H. Preparing new nurses with complexity science and problem-based learning. Journal of Nursing Education. 2011; 50 (1): 7-13.http://dx.doi.org/10.3928/01484834-20101029-01

[42] Silén C. Responsibility and independence in learning - what is the role of the educators and the framework of the educational programme? In Improving Student Learning - Theory research and Practice. C Rust ed. Oxford: The Oxford Centre for Staff and Learning Development; 2003; 249-262. 